\title{
Current
}

Microbiology

\section{Acetobacter pasteurianus strain AB0220: cultivability and phenotypic stability over 9 years of preservation}

\begin{tabular}{|r|l|}
\hline Journal: & Current Microbiology \\
\hline Manuscript ID: & CMB-12-01-0094.R2 \\
\hline Danuscript Type: & Original Manuscripts \\
\hline Complete List of Authors: & $\begin{array}{l}\text { Gullo, Maria; University of Modena and Reggio Emilia, Dept. Agricultural } \\
\text { and Food Science } \\
\text { Mamlouk, Dhouha; University of Modena and Reggio Emilia, Department of } \\
\text { Agricultural and Food Sciences } \\
\text { De Vero, Luciana; University of Modena and Reggio Emilia, Department of } \\
\text { Agricultural and Food Sciences } \\
\text { Giudici, Paolo; University of Modena and Reggio Emilia, Department of } \\
\text { Agricultural and Food Sciences }\end{array}$ \\
\hline Keywords: & acetic acid bacteria, Acetobacter pasteurianus, preservation \\
\hline
\end{tabular}


1 Acetobacter pasteurianus strain AB0220: cultivability and phenotypic stability over 9 years of

2 preservation

\section{Abstract}

4 Acetobacter species are members of the $\alpha$-subclass of Proteobacteria, which harbors a large number

5 of bacteria recalcitrant to cultivation. Strain AB0220 was isolated from a superficial acetification

6 system and preserved for 9 years by short and long time methods. Under short time preservation it

7 was estimated that 540.54 number of generations occurred, whereas in long time preservation

8 conditions the number of generations was 17.40. Ethanol oxidation to acetic acid was stable and

9 confirmed, as well as acetate assimilation during long time preservation. Cultivability checks showed

10 persistence of phenotypic traits (growth on ethanol and methanol, growth on different carbon sources

11 and cellulose production) over the extended preservation time. 16S rRNA gene sequences analysis

12 showed $100 \%$ of similarity with Acetobacter pasteurianus (Accession number GQ240636). Stability

13 of subcultures related to the culture age and subcultures frequency, tested by ERIC/PCR, confirmed

14 the suitability of long term preservation at least over a period of 9 years.

15 Keywords: acetic acid bacteria, preservation, phenotypic stability, Acetobacter pasteurianus

16 Introduction

17 Acetobacter species are members of the $\alpha$-subclass of Proteobacteria, which harbours a large number

18 of bacteria recalcitrant to cultivation. Many strains are difficult to preserve especially those isolated

19 from industrial acetification systems that are high acetic acid (AcOH) tolerant [10]. However, 20 maintenance of "authentical" strains over the preservation time is a priority for microbial exploitation 21 as bio-factory [17]. Acetic acid bacteria (AAB) preservation can be performed by short time and long 22 time methods. By short time preservation (STP), cultures are maintained by renewals generally at $23+4^{\circ} \mathrm{C}$, so they are cyclically on growing status with high probability of mutations inducing or not 24 phenotypic changes [6]. Thus, phenotypic features of interest need to be periodically checked. To 25 preserve phenotypic and genotypic traits of industrial strains, long time preservation (LTP) has been 26 conducted by freeze-drying, ultrafreezing and ultralow-temperature of both pure and starter cultures. 
1 On one side, LTP improves strains stability, but on the other side it strongly affect cell recovery [14,

2 15]. The stability of important traits has been widely studied within AAB, showing high frequency of

3 phenotypic changes, mainly regarding ethanol (EtOH) oxidation and $\mathrm{AcOH}$ resistance. In the

4 Acetobacter pasteurianus species, high rate of spontaneous mutants deficient in EtOH oxidation due

5 to an inserted sequence of $1.665 \mathrm{bp}$ were observed [19]; high frequencies of mutation was also

6 reported for the strain NBRC 3283, where 74 copies of the same inserted sequence were found [2].

7 Other studies have been done to elucidate the mechanisms of $\mathrm{AcOH}$ resistance during exposure to

8 stressors. In Acetobacter and Gluconacetobacter it was shown that genes aarA and aarC of the gene

9 cluster aarABC are responsible for acetate assimilation [5]. Since Acetobacter and

10 Gluconacetobacter members survive without assimilation of acetate under high concentration of

$11 \mathrm{AcOH}$, other mechanisms have been investigated proving that in A. aceti and A. pasteurianus species

12 a proton motive force-dependent and $\mathrm{ABC}$-transporter-like efflux pump systems occur for $\mathrm{AcOH}$

13 [12]. Moreover changes in membrane lipid composition have been reported as additional mechanism

14 for AcOH resistance [20]. Strain stability can be evaluated on the basis of phenotype or genotype

15 with different approaches. Phenotypic assay is dictated by specific traits of the organism. While,

16 genotypic assays are based on a variety of DNA typing methods. Among them, ERIC/PCR has been

17 described as fingerprinting tool providing specific pattern over the time from the same organism and

18 applied to map insertion sequences, such as mutations caused by transposon insertions [9, 11, 21]. In

19 this work, cultivability of the strain AB0220 was investigated with respect to phenotypic and genetic

20 stability in STP and LTP conditions.

\section{Materials and methods}

\section{Organisms and culture conditions}

23 Strain AB0220 was isolated on GYC medium according to previous study [7]. STP was implemented

24 by cultivation cycles on GYC plates incubated at $+28^{\circ} \mathrm{C}$ and stored at $+4^{\circ} \mathrm{C}$; whereas $\mathrm{LTP}\left(-80^{\circ} \mathrm{C}\right)$

25 was conducted mixing $700 \mu \mathrm{l}$ of glycerol at $(50 \%(\mathrm{v} / \mathrm{v}))$ and $300 \mu \mathrm{l}$ of bacterial culture (Fig. 1a).

26 Revitalization was done transferring aliquots $(500 \mu \mathrm{l})$ on GYC tubes. Recovery was scored as 
1 positive if at least one colony or visible biofilm was observed on plates after incubation at $+28^{\circ} \mathrm{C}$.

2 Reference strains were cultivated according to manufacturer indications (DSMZ: Deutsche

3 Sammlung von Mikroorganismen und Zellkulturen $\mathrm{GmbH}$ ). To determine the generation time, total

4 number of cells was enumerated using Neubauer counting chamber (BRAND GMBH and CO KG,

5 Germany). Generation number was calculated from the logarithmic equation $n=\log$ (Nt final/Nt

6 initial)/log2, where $n$ is the generation number, Nt final is the total number of cells at final time and

7 Nt initial is the total number of cells at initial time.

\section{Phenotypic characterization}

9 Cell shape, gram and $\mathrm{KOH}$ tests, catalase production, formation of water-soluble brown pigments

10 and cellulose production were tested as previously described $[18,22]$. Oxidation of EtOH and

11 acetate assimilation was tested by chalk-EtOH tests on Frateur and modified Carr and Passmore

12 media [13]; colorimetric assay was performed by Carr medium [3]. Growth on GYC, AE, YPM and

13 RAE was performed according to [7, 16]. Growth on D-glucose $(20,25,30(\% \mathrm{w} / \mathrm{v}))$ was tested on

14 SM broth according to previous study [13]. Utilization of EtOH and methanol as carbon source was

15 tested on salt agar medium [16]. Acetification ability was assayed on GYC at $2 \%$ of EtOH (v/v) for

$16168 \mathrm{~h}$ following by a scaling-up on sterile red wine $(12 \% \mathrm{EtOH}(\mathrm{v} / \mathrm{v}))$. Acetic acid (g/L) was

17 determined neutralizing samples at $\mathrm{pH} 7.2$ with $0.1 \mathrm{~N}$ of $\mathrm{NaOH}$.

18 Typing of subcultures by ERIC/PCR

19 ERIC/PCR was performed on genomic DNA (gDNA) from cultures by sodium dodecylsulfate (SDS)

20 proteinase-cethyltrimethyl ammonium bromide $(\mathrm{CTAB})$ treatment and preserved at $-20^{\circ} \mathrm{C}$ as

21 previously reported [7]. The value of reproducibility was estimated by analysis of two repeated DNA

22 extracts. Two independent amplifications were performed using the conditions as described earlier

23 [21] with modifications. PCR mix contained $30 \mathrm{ng} / \mu \mathrm{L}$ DNA, 1x Colorless GoTaq® buffer (Promega,

$24 \mathrm{USA}$ ), $4 \mathrm{mM} \mathrm{MgCl}$ (Fermentas), $0.2 \mathrm{mM}$ dNTPs (Takara Bio, Inc., Japan), $0.2 \mu \mathrm{L} \mathrm{BSA} \mathrm{(20} \mathrm{mg/mL,}$

25 Fermentas), $0.4 \mathrm{pmol} / \mu \mathrm{L}$ of each primer and $0.06 \mathrm{U}$ DNA polymerase (Takara Bio, Inc., Japan).

26 Amplification and electrophoresis was performed as previously described [22]. A 100 bp DNA 
1 molecular size marker (GeneRuler ${ }^{\mathrm{TM}} 100$ bp Plus DNA Ladder, Fermentas) was loaded. Gels were

2 stained in ethidium bromide, visualized under UV light and digital image captured using

3 BioDocAnalyze analysis software (Biometra, Göttingen, Germany, version 2.1). Fingerprints were

4 analyzed using the BioNumerics version 6.5 software (Applied Maths, Sint-Martens- Latem,

5 Belgium). The similarity among digitized profiles was calculated using the Pearson correlation, and

6 an average linkage (UPGMA) dendrogram was derived.

7 Partial 16S rRNA gene sequencing and accession number

8 gDNA extraction was performed as described for ERIC/PCR. Direct sequencing and analysis was

9 done on amplicons according to previous study [8]. The nucleotide sequence have been deposited

10 into EMBL databases under the accession number HE650905.

\section{Results}

12 Strain AB0220 was isolated in 2002 during a large spectrum of isolation work aimed to build up an

13 AAB strains collection [7]. Starting from the isolation time, both STP and LTP were implemented.

14 STP was performed on duplicates of AB0220 subcultures. To avoid selecting single colony,

15 transferring from solid medium was performed by streaking part of the hold biofilm of the culture.

16 Rapid growth (within 3 days) with a biofilm formation was observed when cultures were transplanted

17 after 15 days of preservation. After 30 and 60 days of preservation, 5 incubation days to grow on

18 GYC solid and broth were required. Subcultures from extended storage (3 months) grew only on

19 GYC broth. After the first check, frequency between transfers along time was established each 60

20 days. The estimation of the number of generations during 9 years of STP was assessed by

21 reconstruction of the 55 days of preservation. Within the 5-day incubation at $+28{ }^{\circ} \mathrm{C}$, cells number

22 increased 20.45 fold, corresponding to 4.35 generations $(\mathrm{SD}=0.01)$. The total cell number decreased

2314.24 folds after 55 days of storage at $+4^{\circ} \mathrm{C}$ corresponding to a loss of 5.66 generations $(\mathrm{SD}=0.14)$.

24 Subsequently 10.01 generations per passage during STP and thus 540.54 generations occurred.

25 During LTP, viability check performed after 5 months from the first storage showed that 5 incubation

26 days were required when subcultures were revitalized. After the first time, viability check was done 
1 each 24 months. Phenotypic characterization was conducted on current subculture of STP and on

2 subcultures of LTP (AB0220-1 and AB0220-3). Growth was observed on all media except for AE

3 and RAE. No growth on methanol, EtOH and at 30\% of D-glucose was observed (Table 1). Growth

4 on solid media was observed mainly as a soft biofilm on the surface of plates, but differently from

5 the growth modality of the strain DSMZ 2004 for which cellulose layer was visible. Recovery of

6 isolated colonies was often no visible, instead common growth modality was as thin biofilm. In

7 liquid both thin superficial layer and uniform turbidity was observed. Oxidation of EtOH to AcOH

8 and acetate assimilation trialled by chalk-EtOH test was shown by a clear halo around bacterial

9 growth following by a reappearance of opacity on the bottom of the petri dishes due to overoxidation

10 of $\mathrm{AcOH}$ to $\mathrm{CO}_{2}$ and $\mathrm{H}_{2} \mathrm{O}$. By colorimetric assay production of $\mathrm{AcOH}$ was shown by change of

11 indicator from green to yellow and acetate assimilation by change from yellow to blue (Table 2).

12 Amount of $\mathrm{AcOH}$ produced, tested using GYC at $2 \%$ of EtOH followed by periodical addition of

13 wine, produced a gradual increase of $\mathrm{AcOH}$ until 68,26 $( \pm 0.26) \mathrm{g} / \mathrm{L}$ (Fig. 2). Typing by ERIC/PCR

14 on gDNAs was performed on subcultures of STP (from 1 to 5) and LTP (AB0220-1, AB0220-2 and

15 AB0220-3). The number of bands was ranging from 9 to 14 sizing from 2621 to $99 \mathrm{bp}$. Differences

16 were mainly detected in bands intensity, in particular amplicons from 1000 to 200 bp of STP showed

17 weaker bands respect to those of LTP. Macroscopically, the banding patterns appear very similar;

18 this was confirmed by the dendrogram by which two major clusters were obtained. In particular,

19 fingerprinting similarities showed that STP subcultures were most closely related to each other

20 (97\%); slightly lower similarities (96\%) were observed within LTP cluster. The nearly complete 16S

21 rRNA gene sequence of AB0220-3 was obtained (HE650905) and analyzed. Sequence showed 100\%

22 of similarity with A. pasteurianus (A. number GQ240636).

\section{Discussion}

24 Nowadays, there is a need to have cultivable and phenotipically stable AAB to be exploited as

25 biocatalysts in a number of biotechnological applications. For AAB, the bottleneck is mainly due to 26 the instability of key traits, such as: $\mathrm{EtOH}$ oxidation and $\mathrm{AcOH}$ resistance. Strain $\mathrm{AB} 0220$ 
1 (subculture AB0220-2) was successfully applied as selected starter culture, where it produced $60 \mathrm{~g} / \mathrm{L}$

2 of $\mathrm{AcOH}$ [8]. In this study $\mathrm{AcOH}$ production and acetate assimilation, were assayed on $\mathrm{AB} 0220-1$

3 and AB0220-3 (1 year and 9 years of preservation, respectively) and on the current subculture of

4 STP. By chalk-EtOH tests results were unambiguous concerning to EtOH oxidation, while the further

5 oxidation of $\mathrm{AcOH}$ required 7 days for LTP subcultures and it taken more time for STP ones. Using

6 bromocresol medium, oxidation of $\mathrm{AcOH}$ was detected after 72 hours for the LTP subcultures and

7 about 168 hours for STP. The acetate assimilation is distinctive for members of AAB providing

8 useful information on phenotypic stability [4, 3]. Metabolically it is caused by increasing activity of

9 Krebs cycle enzyme and also by increased NADH oxidase activity, as a sophisticated strategy to

10 survive in acetate stress environment [12]. Since both traits can be lost during preservation, they

11 should be routinely tested. Although stability of phenotypic traits was generally confirmed,

12 subcultures of STP required more time and some misinterpretation occurred (as in the case of acetate

13 assimilation). Previous works stated that characteristics of AAB are strongly affected by the "history"

14 of strains [15]. For instance, tolerance to $\mathrm{EtOH}$ and $\mathrm{AcOH}$ decreased when isolates have been used as

15 inocula kept for long time in STP. Whereas high tolerance was observed for strains used immediately

16 after the isolation. This inconsistency has been correlated to the genetic instability of strains. To

17 clarify the mutability, A. pasteurianus (NBRC 3283), which forms a multiphenotype cell complex,

18 was subjected to genome DNA sequencing. The genome analysis revealed more than 280

19 transposons and five genes with hyper-mutable tandem repeats as common features in the genome

20 that consists of a $2.9-\mathrm{Mb}$ chromosome and six plasmids which were recognised as characteristics

21 leading to the hyper-mutability [2]. In this study, stability of subcultures related to the culture age and

22 subcultures frequency was tested by ERIC/PCR. Fingerprintings were stable in term of size and

23 number of bands but in the case of STP subcultures, bands intensity was weakly respect to LTP

24 subcultures over repetition assays. Reasons could be explained by genetic damage and mutations as

25 described for wild type cells and mutants of E. coli for which decrease of bands intensity or

26 disappearance of bands on modified DNA occurred when alterations were higher than 2\% [1]. In the 
1 case of $\mathrm{AB} 0220$ we estimated that 10.01 generations per passage during STP and thus 540.54

2 generations occurred with the 9 years that could be responsible for mutations events inducing 3 phenotypic instability. Although the high similarities (above 96\%) detected by ERIC profiles

4 clustering, the extended response to assays and the decreases of bands intensity observed could be

5 related to the instability generated by the high number of generations occurred along 9 years of STP.

6 Instead phenotypic and genotypic data on LTP subcultures, for which the number of generation

7 occurred was 17.40 , confirms the suitability of LTP by at least over a period of 9 years for AAB

8 belonging to A. pasteurianus species from superficial acetification processes.

\section{Acknowledgements}

10 This work was granted by the European Communities (Project WINEGAR, Cooperative 11 Research/6th Framework Programme) and Manodori Foundation, Italy.

\section{References}

13 [1] Atienzar FA, Venier P, Jha AN et al (2002) Evaluation of the random amplified polymorphic 14 DNA (RAPD) assay for the detection of DNA damage and mutations. Mutat Res 521:151-63

15 [2] Azuma Y, Hosoyama A, Matsutani M et al (2009) Whole-genome analyses reveal genetic 16 instability of Acetobacter pasteurianus Nucleic Acids Res 37:5768-5783

17 [3] Carr JG, Passmore SM (1979) Methods for identifying acetic acid bacteria. In: Skinner FA, 18 Lovelock DW (ed) Identification Methods for Microbiologists. Academic Press., UK, pp 33-47

19 [4] Cleenwerck I, De Vos P (2008) Polyphasic taxonomy of acetic acid bacteria: an overview of the 20 currently applied methodology. Int J Food Microbiol 125:2-14

21 [5] Fukaya M, Takemura H, Tayama K et al (1993) The aarC gene responsible for acetic acid 22 assimilation confers acetic acid resistance on Acetobacter aceti. J Ferment Bioeng 76:270-275

23 [6] Gherna R, Reddy CA. (2007) Culture preservation. In Reddy CA, Terry J, Beveridge JA et al (ed)

24 Methods for general and molecular microbiology pp. 1019-1035

25 [7] Gullo M, Caggia C, De Vero L et al (2006) Characterization of acetic acid bacteria in "traditional 26 balsamic vinegar". Int J Food Microbiol 106:209-212 
1 [8] Gullo M, De Vero L, Giudici P (2009) Succession of selected strains of Acetobacter pasteurianus

2 and other acetic acid bacteria in traditional balsamic vinegar. Appl Environ Microbiol 75:2585-2589

3 [9] Kang HP, Dunne WM (2003) Stability of repetitive-sequence PCR patterns with respect to

4 culture age and subculture frequency. J Clin Microbiol 41:2694-2696

5 [10] Kittelman M, Stamm WW, Follmann H et al (1989) Isolation and classification of acetic acid

6 bacteria from high percentage vinegar fermentations. Appl Bicrobiol Biotech 30:47-52

7 [11] Lupski J, Weinstock GM (1992) Short, interspersed repetitive DNA sequences in prokaryotic 8 genomes. J Bacteriol 174:4525-4529

9 [12] Matsushita K, Toyama H, Adachi O (2004) Respiratory chains in Acetic acid bacteria:

10 Membrane bound periplasmic sugar and alcohol respirations. In Zannoni D (ed) Respiration in

11 Archaea and Bacteria. Advances in Photosynthesis and Respiration, Springer, Dordrecht, pp 81-99

12 [13] Sievers M, Swings J (2005) Family Acetobacteraceae, Ed. In: Garrity GM (ed) 2nd Bergey’s

13 manual of systematic bacteriology, Springer, New York, pp 41-95

14 [14] Sievers M, Teuber M (1995) The microbiology and taxonomy of Acetobacter europaeus in

15 commercial vinegar production. J Appl Bacteriol 79:84S-95S

16 [15] Sokollek SJ, Hertel C, Hammes WP (1998) Cultivation and preservation of vinegar bacteria. J

17 Biotech 60:195-206

18 [16] Sokollek SJ, Hertel C, Hammes WP (1998) Description of Acetobacter oboediens sp. nov., and

19 Acetobacter pomorum sp. nov., two new species isolated from industrial vinegar fermentations. Int J

20 Syst Bacteriol 48:935-940

21 [17] Stackebrandt E (2010) Diversification and focusing: strategies of microbial culture collections.

22 Trends Microbiol 18:283-287

23 [18] Swings J, Gillis M, Kersters K (1992) Phenotypic identification of acetic acid bacteria. In: Board

24 RG, Jones D, Skinner FA (eds) Identification methods in applied and environmental microbiology.

25 Blackwell Scientific, Oxford, pp 103-110 
1 [19] Takemura H, Horinouchi S, Beppu T (1991) Novel insertion sequence IS1380 from Acetobacter

2 pasteurianus is involved in loss of EtOH-oxidizing ability. J Bacteriol 173:7070-7076.

3 [20] Trcek J, Jernejc K, Matsushita K (2007) The highly tolerant acetic acid bacterium

4 Gluconacetobacter europaeus adapts to the presence of acetic acid by changes in lipid composition,

5 morphological properties and PQQ-dependent ADH expression. Extremophiles 11:627-635

6 [21] Versalovic J, Koeuth T, Lupski JR (1991) Distribution of repetitive DNA sequences in

7 eubacteria and application to fingerprinting of bacterial genomes. Nucleic Acids Res 19:6823-6831

8 [22] Wu J, Gullo M, Chen F et al (2010) Diversity of Acetobacter pasteurianus strains isolated from

9 solid-state fermentation of cereal vinegars. Curr Microbiol 60:280-286

\section{Legend to figures}

11 Fig. 1 Design of STP and LTP (a) and dendrogram generated by ERIC/PCR (b)

12 (a) Subcultures of LTP were named AB0220-1, AB0220-2 and AB0220-3; (b) STP-1, STP-2, STP-3

13 replicates of STP subculture transplanted on June 2011; STP-4 and STP-5 replicates of STP

14 subculture transplanted in November $2011 ; 3509^{\mathrm{T}}$ A. pasteurianus (DSMZ).

15 Fig. 2. Acetic acid production of AB0220-3 in wine

16 Different volume of wine was added in correspondence of arrows.

17 The data are averages based on three trials, and error bars indicate the standard deviation (SD). 
Table 1 Phenotypic characteristic of AB0220

\begin{tabular}{ll}
\hline Feature & ${ }^{\mathrm{a}} \mathbf{A B 0 2 2 0}$ \\
\hline Shape & rod \\
Gram reaction & - \\
KOH reaction & + \\
Catalase reaction & + \\
Water-soluble pigments & - \\
Production of acetic acid & + \\
Oxidation of acetic acid to $\mathrm{CO}_{2}$ and $\mathrm{H}_{2} \mathrm{O}$ & + \\
Growth on: & \\
${ }^{\mathrm{b}}$ Ethanol & - \\
${ }^{\mathrm{b} M e t h a n o l ~}$ & - \\
Growth on culture media: & \\
GYC & + \\
AE & - \\
YPM & + \\
RAE & - \\
Frateur medium & + \\
Modified Passmore and Carr & + \\
Carr medium & + \\
${ }^{\mathrm{c} C e l l u l o s e ~ p r o d u c t i o n ~}$ & - \\
Growth on D-glucose $(\%)$ & \\
20 & + \\
25 & + \\
30 & - \\
\hline
\end{tabular}

${ }^{\mathrm{a}}$ Assays were conducted on AB0220-1 and AB0220-3 subcultures

${ }^{\mathrm{b}} \mathrm{DSMZ} 11825^{\mathrm{T}}$ (A. pomorum) was used as control

${ }^{\mathrm{c} D S M Z} 2004$ (Ga. xylinus) was used as control

Table 2 Oxidation of ethanol and acetic acid

\begin{tabular}{|c|c|c|c|c|c|c|c|c|c|}
\hline \multirow[t]{2}{*}{ Strain } & \multicolumn{3}{|c|}{ Frateur medium } & \multicolumn{3}{|c|}{$\begin{array}{c}\text { Modified Carr and Passmore } \\
\text { medium }\end{array}$} & \multicolumn{3}{|c|}{ Carr medium } \\
\hline & Growth & $\begin{array}{c}\mathrm{AcOH} \\
\text { formation }\end{array}$ & $\begin{array}{c}\mathrm{AcOH} \\
\text { assimilation }\end{array}$ & Growth & $\begin{array}{c}\mathrm{AcOH} \\
\text { formation }\end{array}$ & $\begin{array}{c}\mathrm{AcOH} \\
\text { assimilation }\end{array}$ & Growth & $\begin{array}{c}\mathrm{AcOH} \\
\text { formation }\end{array}$ & $\begin{array}{c}\mathrm{AcOH} \\
\text { assimilation }\end{array}$ \\
\hline AB0220-3 & 24 & 24 & 120 & 24 & 24 & 96 & 24 & 24 & 72 \\
\hline${ }^{\mathrm{a}} 3509^{\mathrm{T}}$ & 48 & 72 & 168 & 48 & 72 & 168 & 24 & 24 & 72 \\
\hline${ }^{b} 3503^{\mathrm{T}}$ & 48 & 48 & - & 48 & 48 & - & 24 & 24 & - \\
\hline
\end{tabular}

${ }^{\mathrm{a}} \mathrm{DSMZ} 3509^{\mathrm{T}}$ (A. pasteurianus);.

${ }^{\mathrm{b}} \mathrm{DSMZ} 3503^{\mathrm{T}}$ (Gluconobacter oxydans) 


\section{Page 11 of 12}

\section{Current Microbiology}

Fig. 1 Design of STP and LTP (a) and dendrogram generated by ERIC/PCR (b)

a

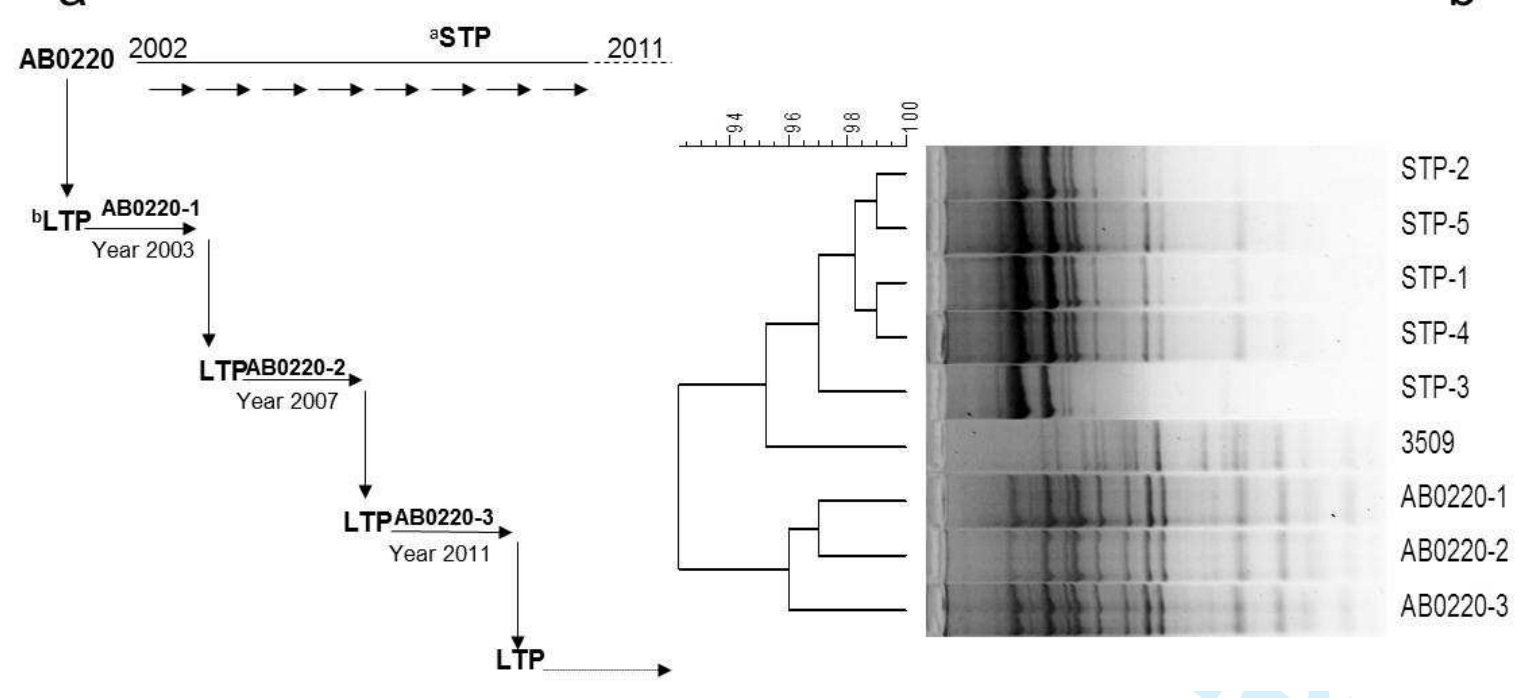


Fig. 2 Acetic acid production of AB0220-3 in wine

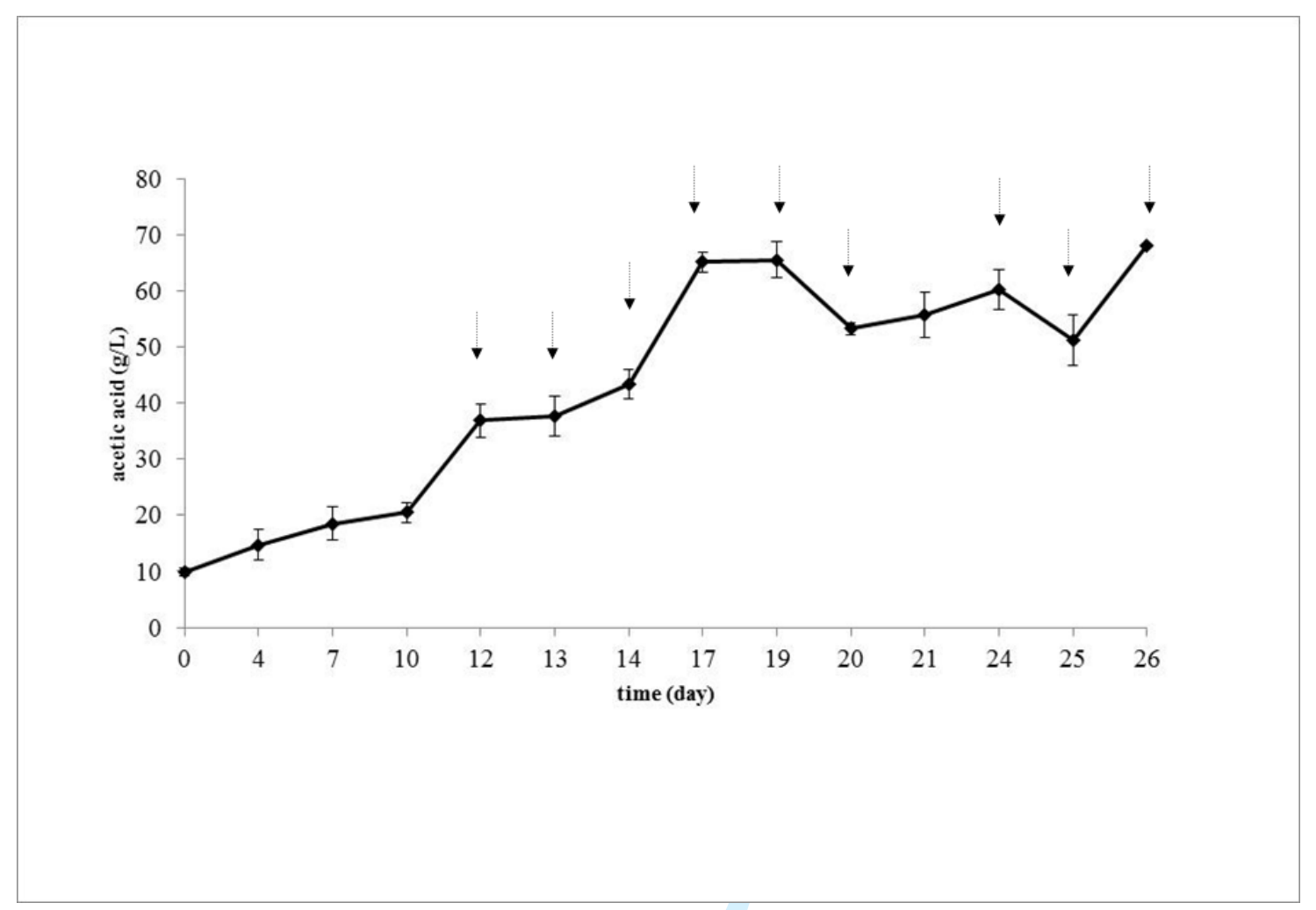

